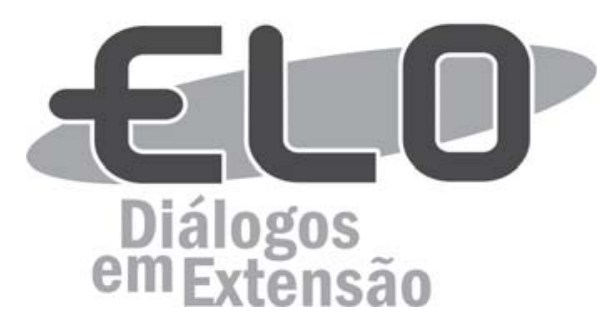

\title{
Extensão universitária e formação acadêmica: alguns apontamentos sobre os cinco anos de vigência do Programa de Bolsas de Apoio à Cultura e à Arte da UFVJM
}

José Rafael Madureira ${ }^{1}$

\begin{abstract}
Resumo: Qual é o sentido da cultura e da arte na formação acadêmica dos estudantes? Essa indagação éo ponto de partida das discussões apresentadas neste artigo e elaboradas com base na análise de dados levantados sobre os cinco anos de vigência do Procarte (2012-2017), um programa específico de apoio destinado aos projetos de extensão vinculados às áreas da cultura e da arte e desenvolvido pela Pró-Reitoria de Extensão e Cultura da Universidade Federal dos Vales do Jequitinhonha e Mucuri (UFVJM). O cruzamento de todo material pesquisado (documentos oficiais, resoluções, regulamentos e editais de programas, planilha de projetos aprovados, quadros de resultados finais) possibilitou a organização de um conjunto de apontamentos sobre esse programa que poderá contribuir não apenas na sua avaliação diagnóstica, como também com os debates sobre o papel da extensão universitária nos processos de formação cultural e acadêmica dos estudantes.
\end{abstract}

Palavras-chave: Extensão universitária. Programas de apoio. Arte. Cultura. Formação acadêmica.

Área Temática: Educação e Cultura.

\section{University extension and high education: some notes on the 5 years of the Program of Scholarships to Support Culture and Art of UFVJM}

Abstract: What is the meaning of culture and art in the College education of students? This question is the starting point of the reflections brought to this article based on the data collected over the five years of the Procarte (2012-2017), a specific support program for extension projects related to the area of culture and art developed by the Pro-Rectory of Extension and Culture of the Federal University of the Jequitinhonha and Mucuri Valleys (UFVJM). The analysis and cross-checking of all researched material (official documents, resolutions, regulations and program notices, project worksheets, results tables) made it possible to construct a set of notes on this program, which should contribute not only to the evaluation of it as well as with the debates about the role of university extension in the processes of cultural and College education of students.

Keywords: University Extension. Support programs. Art. Culture. College education.

\section{Extensión universitaria y formación académica: algunos apuntes sobre los 5 años de vigencia del Programa de Becas de Apoyo a la Cultura y al Arte de la UFVJM}

Resumen: ¿Cual es el sentido de la cultura y el arte en la formación académica? Esta problematización es el punto de partida de las discusiones presentadas en este texto que fue elaborado com base em los datos de los primeros años en la vigilancia del PROCARTE (2012-2017), un programa de apoyo a los proyectos de extensión relacionados con la cultura y el arte desenvolvido pela Pró-Reitoria de Extensão y Cultura de la Universidade Federal dos Vales do Jequitinhonha e Mucuri (UFVJM). O cruzamento de todo el material pesquisado (documentos oficiales, resoluciones, reglamentos y editais de programas, planeación de proyectos aprobados,

${ }^{1}$ Professor do Instituto de Ciências Humanas, Comunicação e Artes da Universidade Federal de Alagoas. Av. Lourival Melo Mota, s/n - Tabuleiro do Martins Maceió/AL - CEP. 57.072-900 - Tel. (82) 3214-1100. E-mail: joserafaelmadureira@gmail.com 
quadros de resultados finales) permitió la organización de un conjunto de notas sobre el programa que puede ayudar en la evaluación diagnóstica del PROCARTE, como también con los debates sobre el papel de la extensión universitaria en los procesos de formación cultural y académica de los estudiantes.

Palabras clave: Extensión Universitaria. Programas de apoyo. Arte. Cultura. Formación académica.

\section{Introdução}

Qual é o sentido da cultura e da arte na formação acadêmica dos estudantes? Essa indagação é o ponto de partida das discussões apresentadas neste texto com o intuito de contribuir com os debates sobre extensão universitária e formação cultural.

Formação é um termo imbuído de grande plasticidade. Formação, de formatione, "é a ação de dar forma" (SARAIVA, 2006, p. 499). No contexto do romantismo alemão, formação não é apenas cultura, formação é Bildung, "um processo de fortíssima conotação pedagógica, educativa e estética; é um processo e também o seu resultado" (BERMAN, 2002, p. 79).

Todo estudante, ao sair da universidade, deveria ser capaz de discutir com autonomia e rigor acadêmico-científico os mais variados assuntos. Enfim, ele deveria ser culto (Gebildet), o que só seria possível através de uma imersão nas formas mais elaboradas do acervo histórico-cultural da humanidade, seus três grandes e indissociáveis campos: "a filosofia, a ciência e a arte" (SAVIANI; MARTINS; CARDOSO, 2015, p. 176). Não por acaso, a tradição acadêmica europeia atribui aos graduados em ciências humanas o título de Bachelor of Arts (Bacharel em Artes) e, aos doutores, o título de Philosophiæ Doctor (Doutor em Filosofia), independentemente da área de conhecimento.

Essa concepção romântica de educação entrou em franco declínio em meados do século XIX, um processo de embotamento da formação acadêmica que fragmentou os saberes clássicos em incontáveis subprodutos (disciplinas) destinados a especialistas e especialidades.

A arte e a filosofia, por exemplo, se tornaram um domínio quase exclusivo dos estudantes de artes e filosofia, respectivamente. Já a cultura, que para Mário de Andrade (2005, p. 269) "é tão necessária como o pão", parece ser assunto restrito à área de ciências humanas, como se as instigantes e sempre atuais discussões sobre esse tema não favorecessem a formação de profissionais mais preparados para enfrentar as exigências e desafios do mercado, independentemente de sua área de formação.

A Universidade Federal dos Vales do Jequitinhonha e Mucuri (UFVJM) possui quatro campi (Janaúba, Unaí, Teófilo Otoni e Diamantina) e 11 unidades acadêmicas, oferecendo 45 cursos presenciais de graduação, quatro na modalidade à distância e inúmeros programas de pós-graduação lato e stricto sensu. Esses cursos abarcam oito áreas do conhecimento: Ciências Humanas, Engenharias, Ciências Sociais Aplicadas, Letras, Ciências Biológicas, Ciências Exatas, Ciências da Saúde e Ciências Agrárias.

A área de Artes, como se observa, não se encontra presente. Essa lacuna é especialmente dramática para a área de abrangência da UFVJM, situada em uma região socioeconômica desfavorecida. Roberto Amaral, Diretor de Cultura da UFVJM entre 2015 e 2016, afirmou que a inexistência de cursos de artes é "um ponto negativo para a instituição" (2016, p. 35). De fato, para grande parte da comunidade acadêmica, o acesso à cultura e à arte dar-se-á por meio de ações extensionistas, o que é dificultado pela falta de profissionais devidamente qualificados nessas áreas e estruturas físicas apropriadas.

A análise de todas as estruturas curriculares dos cursos de graduação da UFVJM demonstrou que somente uma unidade curricular específica de Artes é ofertada, no caso, a Dança, vinculada à licenciatura e ao bacharelado em Educação Física. Alguns cursos da área de Ciências Humanas e Ciências Sociais Aplicadas, ainda que não ofereçam disciplinas específicas de Artes Visuais, Música, Artes Cênicas ou Cinema, buscam uma aproximação: Sociologia da Cultura e da Arte (Bacharelado em Humanidades), História da Arte (Turismo), Arte-Educação (Bacharelado em Humanidades), Literatura e outras Artes (Letras), Arte e Cultura (Bacharelado em Humanidades).

A área de Letras, evidentemente, desenvolve rigorosos estudos e práticas de literatura e linguagem, mas é preciso fazer uma distinção entre Literatura e Artes, duas áreas do conhecimento que possuem tradições acadêmicas muito particulares. O mesmo se observa na História da Arte, uma área que circunscreve somente os estudos sobre a história da Pintura e da Escultura, deixando de lado outras linguagens, como a Música e as Artes Cênicas. 
A arte, de forma institucionalizada ou não, sempre esteve presente na universidade desde os primórdios da Alma Mater Studiorum, fundada em 1088 sob a égide da escolástica. Todavia, áreas mais específicas como, por exemplo, a Música, reclamam certos pré-requisitos de seu corpo de docentes e técnicos, sem contar os laboratórios (salas de ensaio, estúdios de gravação) e equipamentos específicos (instrumentos musicais), cuja aquisição, em geral, encontra-se atrelada às demandas dos cursos de graduação.

As discussões de Moita e Andrade (2009) são especialmente importantes como ponderação sobre esse problema, afinal, como conquistar, nesse contexto da UFVJM, a esperada indissociabilidade entre ensino, pesquisa e extensão na área de Artes?

Para minimizar essa situação, a Pró-Reitoria de Extensão e Cultura da UFVJM criou, em 2012, o Procarte, um programa específico de apoio aos projetos de extensão vinculados às áreas da cultura e da arte. O proposito deste artigo é discutir o lugar da arte e da cultura na formação acadêmica dos estudantes e apresentar alguns apontamentos sobre os cinco primeiros anos de vigência desse programa extensionista (2012-2017).

\section{Programas de bolsas de apoio aos projetos de extensão}

Inúmeras ações são realizadas junto à Pró-Reitoria de Extensão e Cultura da UFVJM: cursos, oficinas, palestras, seminários, eventos e projetos. Em relação aos projetos, dois programas de apoio e incentivo são desenvolvidos: o Programa Institucional de Bolsas de Extensão (Pibex) e o Programa de Bolsas de Apoio à Cultura e à Arte (Procarte).

O Pibex é um programa já consolidado e desenvolvido em várias universidades brasileiras. Conforme os registros da Diretoria de Extensão da UFVJM, desde 2012 foram lançados 12 editais $^{1}$ (Tabela 1). Esses dados são bastante expressivos para uma universidade com apenas 12 anos de existência, indicando que 548 projetos foram aprovados e, consequentemente, desenvolvidos em prol do crescimento e amadurecimento da extensão universitária e de suas interfaces com a comunidade.

Os projetos apresentados ao Pibex devem vincular-se a uma das oito áreas temáticas previstas no Regulamento das Ações de Extensão (Comunicação, Cultura, Direitos Humanos e Justiça, Educação, Meio Ambiente, Saúde, Tecnologia e Produção, Trabalho), além de indicar a área do conhecimento prevista pelo Conselho Nacional de Desenvolvimento Científico e Tecnológico (CNPq).

Essa Pró-Reitoria, além da Diretoria de Extensão, responsável pela gestão do Pibex, conta com uma Diretoria de Cultura, órgão criado para tratar das ações ligadas à produção cultural. A equipe desse setor específico, num esforço coletivo, concebeu o Procarte, um programa que tem como disposição preliminar o "desenvolvimento de estratégias que ampliem o horizonte de contato da comunidade acadêmica com as diversas expressões culturais e artísticas" (PROCARTE, 2017, p. 1), ressaltando ainda que o acesso à arte e à cultura "é um direito constitucional e condição fundamental para o exercício da cidadania" (ibidem).

Tabela 1 - Informações sobre os editais do Pibex publicados entre 2012 e 2017

\begin{tabular}{|c|c|c|c|}
\hline Editais publicados & Projetos inscritos & Bolsas ofertadas & Projetos aprovados \\
\hline $001 / 2012$ & 57 & 80 & 57 \\
\hline $002 / 2012$ & 12 & 18 & 12 \\
\hline $003 / 2012$ & 24 & 26 & 24 \\
\hline $001 / 2013$ & 77 & 60 & 60 \\
\hline $002 / 2013$ & 69 & 43 & 43 \\
\hline $001 / 2014$ & 93 & 51 & 51 \\
\hline $002 / 2014$ & 79 & 50 & 50 \\
\hline $001 / 2015$ & 81 & 50 & 50 \\
\hline $002 / 2015$ & 116 & 51 & 51 \\
\hline $001 / 2016$ & 58 & 50 & 50 \\
\hline $002 / 2016$ & 126 & 50 & 50 \\
\hline $001 / 2017$ & 106 & 50 & 50 \\
\hline 12 & 989 & 579 & 548 \\
\hline
\end{tabular}

Fonte: Tabela elaborada com base na planilha disponibilizada pela Diretoria de Extensão (Proexc/UFVJM). 


\section{Informações gerais sobre o Procarte}

O Procarte foi aprovado pelo Conselho de Ensino, Pesquisa e Extensão da UFVJM através da Resolução $n^{\circ} 27$ de 19 de outubro de 2012, e o primeiro edital foi lançado ao final de 2012. Entre 2012 e 2017, 10 editais foram publicados, e 79 propostas ligadas à cultura e à arte foram aprovadas (Tabela 2). Importante esclarecer que, até o Edital 001/2014, somente os cinco primeiros projetos classificados receberiam recursos, pois eram oferecidas duas bolsas por projeto aprovado.

O Procarte foi escrito com base na Política Cultural da UFVJM (Resolução ${ }^{\circ} 26$ do CONSEPE de 19 de outubro de 2012), e esta se orientou pelo Plano Nacional de Cultura (Lei $n^{\circ}$ 12.343/2010). O programa possui cinco objetivos: "(1) Contribuir com a formação dos discentes a partir da interação com as manifestações culturais e artísticas das regiões de abrangência da UFVJM; (2) Estimular, por meio do fazer cultural-artístico, a formação de público e a valorização dos espaços dedicados à cultura e às artes; (3) Proporcionar e incentivar o respeito às diversas manifestações culturais e artísticas em suas múltiplas funções, identificando-as, relacionando-as e compreendendo-as em seu contexto histórico; (4) Estreitar relações com agentes culturais e artistas das regiões de abrangência da UFVJM e instituições públicas ou privadas com reconhecida experiência em artes; (5) Promover o registro, a valorização e a divulgação de expressões culturais das regiões de abrangência da UFVJM" (PROCARTE, 2017, p. 2).

Tabela 2 - Informações sobre os editais do Procarte publicados entre 2012 e 2017

\begin{tabular}{cccc}
\hline Editais publicados & Projetos inscritos & Bolsas ofertadas & Projetos aprovados \\
\hline $001 / 2012$ & 10 & 10 & 5 \\
$001 / 2013$ & 7 & 10 & 5 \\
$002 / 2013$ & 9 & 10 & 5 \\
$001 / 2014$ & 10 & 10 & 5 \\
$002 / 2014$ & 13 & 10 & 10 \\
$001 / 2015$ & 13 & 10 & 10 \\
$002 / 2015$ & 13 & 10 & 10 \\
$001 / 2016$ & 16 & 10 & 10 \\
$002 / 2016$ & 12 & 10 & 10 \\
$001 / 2017$ & 9 & 10 & 9 \\
10 & 112 & 100 & 79 \\
\hline
\end{tabular}

Fonte: Tabela elaborada com base na planilha disponibilizada pela Diretoria de Extensão (Proexc/UFVJM).

Os projetos podem ser encaminhados por docentes ou técnico-administrativos da UFVJM e deverão vincular-se a uma das oito categorias previstas: Dança, Música, Literatura, Audiovisual, Fotografia, Artes Visuais, Teatro e Artes Integradas. Também é preciso seguir um modelo específico de apresentação de projetos que contém os seguintes tópicos: título, dados gerais sobre a equipe de trabalho, introdução, justificativa, objetivos, metodologia, metas, esclarecimentos sobre a participação de estudantes, público beneficiário, cronograma de execução e referências bibliográficas.

O Procarte oferece o mesmo suporte do Pibex. A cada edital são oferecidos recursos de custeio aos 10 primeiros projetos classificados no valor de $R \$ 3$ mil, e 10 bolsas no valor de $R \$ 400,00$ destinadas aos discentes-bolsistas e concedidas pelo prazo de 12 meses.

Os critérios de seleção e classificação dos projetos previstos pelo Procarte são muito claros,

1) Coerência entre objetivos, metodologia e metas do projeto;2) Viabilidade logística, técnica e operacional da proposta compatível com a infraestrutura existente na UFVJM; 3) Consonância com as metas do Plano Nacional de Cultura; 4) Concordância com os objetivos propostos pelo Regulamento do Procarte e atendimento aos requisitos exigidos; 5) Experiência do coordenador no desenvolvimento de ações de cultura e arte; 6) Parcerias estabelecidas com grupos artístico-culturais existentes (PROCARTE, 2017, p. 7-8).

Em relação aos critérios de desclassificação, consta que: "Projetos com pontuação inferior a $60 \%$ não serão classificados" (ibidem, p. 8). 


\section{Metodologia}

Inicialmente, foi feito um levantamento de todos os dados disponíveis sobre o Pibex e sobre o Procarte entre 2012 e 2017, os editais publicados, seus respectivos anexos (regulamento do Procarte, roteiro para elaboração de projetos, identificação do projeto e equipe executora), além dos 22 quadros com os resultados finais dos dois programas.

Em seguida, foram consultados os seguintes documentos oficiais citados nos editais: Política de Extensão da UFVJM (anexo da Resolução no 06 do CONSEPE de 17 de abril de 2009), Política Cultural da UFVJM e do Procarte (Resolução n 26 do CONSEPE, de 19 de outubro de 2012), Metas do Plano Nacional de Cultura (BRASIL, 2012), Política Nacional de Extensão Universitária (FORPROEX, 2012) e o Regulamento das Ações de Extensão Universitária (PROEXC/UFVJM, 2008).

Entre 2016 e 2017, dando continuidade à coleta de dados, quatro entrevistas foram realizadas: com Silvio Diogo, Produtor Cultural da UFVJM e figura-chave na elaboração do Procarte; com Roberto Amaral, Diretor de Cultura da UFVJM entre 2015 e 2016; com André Covre, Diretor de Extensão da UFVJM; e com Léa Sá Fortes, atual Diretora de Cultura da UFVJM. O roteiro das entrevistas foi delineado a partir de três questões norteadoras: 1) qual é o sentido da extensão universitária?; 2) o que pensa sobre a cultura e sobre a arte como espaços de formação dos estudantes?; e 3) quais são as suas considerações sobre o Procarte?

As entrevistas de Silvio Diogo e Roberto Amaral foram publicadas na íntegra (SANTOS; CARVALHO, 2016); as outras duas, realizadas simultaneamente com André Covre e Léa Sá Fortes em 31/10/2017 na Proexc/UFVJM, foram transcritas para acervo pessoal, sendo a publicação dos trechos aqui citados explicitamente autorizada.

A Diretoria de Cultura da UFVJM também disponibilizou um arquivo contendo informações gerais sobre os 79 projetos aprovados nos editais do Procarte (título do projeto, número de registro, período de execução, objetivos da proposta).

A técnica hermenêutica de Schleiermacher (2008), utilizada durante todo o processo, serviu de suporte teórico para uma interpretação mais objetiva dos dados, ao lado da qual foi disposta a experiência frente à coordenação e avaliação Ad hoc de projetos encaminhados aos editais do Pibex e do Procarte.

\section{Resultados e Discussão}

A análise e o cruzamento de todo material pesquisado (documentos oficiais, resoluções, regulamentos e editais dos programas, planilha de projetos aprovados, quadros de resultados finais) conduziu à construção de um conjunto de apontamentos. Importante esclarecer que um apontamento não é um axioma, mas apenas um registro de ideias e eventos a serem revistos em posteriores reflexões.

\section{Apontamento 1}

Todos os 112 títulos dos projetos apresentados aos editais do Procarte em suas 10 edições (classificados ou não) foram minuciosamente analisados, uma operação hermenêutica que serviu como ponto de partida para vários apontamentos. De acordo com Schleiermacher (2008, p. 33): “A hermenêutica não deve estar limitada meramente às produções literárias". Nesse sentido, uma conversação informal ou mesmo o título de um projeto pode oferecer dados valiosos.

O título de um projeto traduz ou deveria traduzir a essência de uma proposta. Um dos critérios de avaliação dos projetos encaminhados ao Pibex, a propósito, define um total de três pontos somente para o quesito "título do projeto".

A escolha de um título não é casual, ela deflagra uma concepção, uma epistemologia. Títulos acompanhados de longos subtítulos explicativos indicam uma elaboração intelectual mais cientificista, mais fragmentada, mais técnica que deve conduzir os procedimentos metodológicos utilizados na execução das ações extensionistas.

Projetos encaminhados ao Procarte deveriam ser mais criativos, apresentando, por conseguinte, títulos mais concisos, sem tantas explicações desnecessárias. Essa ideia não é absurda, pois vários títulos de projetos aprovados demonstram uma tentativa de síntese: "Cantadores de Histórias"; "Processo Criativo em Dança"; "Encontros Coletivos de Performance"; "Eco dos Vissungos"; "Revista Um Quê"; "Coral Cênico UFVJM"; "Cine Violeta"; "Música nas Praças". 
Cerca de $60 \%$ dos projetos encaminhados ao Procarte apresentam títulos que mais se assemelham ao enunciado de teses e artigos científicos. Alguns exemplos: "Arte (com) ciência: o teatro e a contação de histórias como possibilidades de formação de público, de leitores e de discussão de conhecimentos científicos"; "Ampliando o foco sobre a Atenção Básica: um novo olhar sobre a Saúde da Família e Comunidade"; "Vale a pena contar histórias: ludicidade como metodologia que encanta e contribui para formar leitores para toda a vida"; "Projeto Transver: transvendo o mundo através da inclusão audiovisual na Sociedade Protetora da Infância de Diamantina/MG".

Esses títulos, como vários outros, demonstram uma apropriação da arte e da cultura como meio de realização de metas acadêmico-extensionistas. O uso da conjunção "como" ou do advérbio "através $\mathrm{de}^{\prime \prime 2}$, bastante empregados, coloca a arte e a cultura em uma posição secundária.

O Cinema, por ser um produto acabado e tecnicamente reprodutível, retrata muito bem essa situação, especialmente dentro da instituição escolar. Para Almeida (1994, p. 7),

\begin{abstract}
Quando se fala de cinema, vídeo e televisão, na escola, geralmente encaram-se essas produções como ilustrações, o professor passa um filme para ilustrar o que foi falado. Nesse caso fica evidente que o filme assume um papel secundário, uma espécie de ilustração e imagem inferior ao texto e à explicação oral. [...] Os filmes comerciais são uma produção da cultura, não da pedagogia ou da didática.
\end{abstract}

Essa questão motivou uma diferenciação entre os projetos encaminhados ao Procarte que tomam a cultura e a arte como um meio para a concretização de metas extensionistas e àqueles que se valem da cultura e da arte como princípio e fim das ações.

Os títulos dos projetos foram organizados em duas categorias. A primeira, definida como "arte e cultura como fim das ações", acolheu os projetos que, com muita clareza, situam-se no campo do fazer cultural-artístico previsto no Procarte. Em relação à segunda categoria, definida como "arte e cultura como meio para a realização das ações", foram alocados os projetos que se aproximam da arte de uma forma mais utilitária, tomando-a como estratégia metodológica para a concretização de fins acadêmico-extensionistas.

O resultado encontrado é: $56 \%$ dos projetos situam-se na primeira categoria, enquanto $44 \%$ situam-se na segunda. Esses números indicam que quase a metade dos projetos se apropria da arte e da cultura como um meio e não como um fim das ações, o que parece contrariar as disposições do Procarte.

Alguns projetos traduzem com exatidão a categoria "arte e cultura como fim das ações". Entre eles, destaca-se a "Revista Um Quê", um projeto contemplado pelos editais 001/2015 e 001/2017 do Procarte e que se vale da literatura, da poesia e da fotografia como pontos de partida e chegada, integrando e valorizando a produção de artistas do Vale do Jequitinhonha. Essa "revista" nasceu por iniciativa dos "Encontros Literários: entre palavras, canções e imagens", um projeto contemplado pelos editais 002/ 2013 e 002/2014 do Procarte que também foi escrito e conduzido pelo diálogo direto com a arte.

"Processo Criativo em Dança" é um segundo exemplo da categoria "arte e cultura como fim das ações". Esse projeto, classificado em primeiro lugar por três vezes consecutivas junto ao Procarte (editais 002/2014, 002/2015 e 002/2016), tem como objetivo geral a composição de estudos coreográficos a serem apresentados nas escolas públicas da cidade de Diamantina e região. O projeto, além de propiciar ao elenco formado por estudantes e membros da comunidade externa um espaço de formação artística, oferece aos escolares uma oportunidade de fruição estética, o que deve ser novidade para a maior parte desses jovens espectadores.

O projeto "Espaço Hip Hop: uma estratégia de prevenção ao uso de drogas", encaminhado ao edital 001/2014 do Procarte, pode ser colocado em contraponto ao "Processo Criativo em Dança". O projeto não foi aprovado, mas contribui no entendimento da categoria definida como "arte e cultura como meio para a realização das ações". Nesse caso, o Hip Hop, que envolve a dança, o Rap e o grafite, não são pensados como produções artístico-culturais, mas como estratégias de acolhimento e proteção dos jovens da periferia em situação de vulnerabilidade. 
A proposta é pertinente, mas, ao ser apresentada como "estratégia de prevenção ao uso de drogas", ela se afasta dos objetivos do Procarte. A mesma proposta poderia ter recebido um melhor acolhimento se fosse enviada ao Pibex e cadastrada na área temática $\mathrm{n}^{\mathrm{o}} 6$ (Saúde), através das linhas extensionistas $\mathrm{n}^{\circ} 53$ (Uso de drogas e dependência química) e $\mathrm{n}^{\circ} 30$ (Jovens e adultos), entre outras descritas no Regulamento das Ações de Extensão (PROEXC/UFVJM, 2008).

O projeto "Fotografias e exposição de fotos da Formiguinha de Ouro (Multilidae) na Serra do Espinhaço Meridional", contemplado pelo Edital 002/2013 do Procarte, inspirou mais algumas reflexões. A proposta foi apresentada com o objetivo de fotografar exemplares de um inseto específico da região da Serra do Espinhaço Meridional e produzir uma exposição de modo a contribuir com a preservação da cultura regional por meio da arte. O uso da locução "por meio de" já revela de antemão a posição secundária ocupada pela fotografia.

A equipe executora desse projeto, com grande êxito, conquistou a esperada indissociabilidade entre ensino, pesquisa e extensão, além de promover uma interação cultural entre os estudantes e as comunidades da região, um dado que pode ser consultado no artigo publicado em periódico extensionista (AGUIAR et al., 2016). O trabalho, além de uma substancial discussão teórica sobre campo rupestre e zooterapia, apresenta dez fotografias cuidadosamente produzidas com equipamentos profissionais e técnicas sofisticadas de enquadramento e composição, destacando-se a Figura 5 (ibidem, p. 191). A fotografia aparece inclusive como palavra-chave da publicação, mas será que ela consegue superar o status de "ilustração" da argumentação científica? De qualquer modo, os elementos da linguagem fotográfica não são discutidos em nenhum momento, assim como não há sequer uma obra sobre fotografia nas referências bibliográficas, uma ausência significativa para um trabalho desenvolvido à luz do Procarte.

O diálogo entre ciência e arte é muito frutífero, ou melhor, ele é imprescindível para a conquista de uma meta que é central para ambas: a humanização. A ciência é um produto da cultura, mas não é arte. A arte, como a filosofia e ao contrário da ciência, não tem utilidade. Então, qual seria o sentido da arte? Miguel de Unamuno (1985, p. 5) resolveu esse dilema em uma sentença: “Alguém pega um bonde elétrico para ir à ópera e se pergunta: quem é, nesse caso, mais útil, o bonde ou a ópera?".

O edital do Procarte não deixa brecha para ambiguidades. Em seus objetivos, o termo "culturalartístico" ou "manifestações culturais e artísticas" é repetido inúmeras vezes. O edital também indica que o apoio destina-se aos projetos vinculados à cultura $e$ à arte, e não aos projetos vinculados à cultura ou à arte. A escolha da conjunção aditiva não é casual, pois é compulsório aos proponentes indicar uma das oito linguagens artísticas previstas.

O projeto "Oficinas terapêuticas: uma possibilidade de tratamento para a psiquiatria" é o último exemplo a ser apresentado e discutido sobre a categoria "arte e cultura como meio para a realização das ações". O projeto, classificado pelo programa por duas vezes (Editais 002/2014 e 002/2015), tem como objetivo a realização de oficinas de arte-terapia destinadas aos pacientes do Centro de Atenção Psicossocial (CAPS) de Diamantina como forma de tratamento psiquiátrico. A ideia remete ao trabalho de Nise da Silveira e às palavras de Gérard Bouté (1997, p. 193): “A medicina não tem empatia, analisa sinais. Coloca palavras entre o corpo e a doença".

A proposta é uma contribuição efetiva para a humanização do atendimento aos pacientes e aos seus familiares, mas tratar a arte como "atividade" de pintura, cerâmica, música, desenho e dança evidencia certo afastamento das diretrizes do Procarte. O Pibex, nesse contexto, parece ser um programa mais apropriado para uma ação claramente vinculada à área da Saúde.

A aprovação dessa proposta em dois editais do Procarte pode ser um indício de que não apenas os proponentes, mas a própria comissão avaliadora dos projetos, constituída por membros do Conselho de Extensão e Cultura da Proexc/UFVJM, ainda não tem total clareza da finalidade do programa, ou então, diante da escassez de projetos apresentados, assunto a ser discutido no próximo apontamento, se sente inclinada a fazer certas concessões de modo a não prejudicar o desenvolvimento de um programa em fase de estruturação.

A arte não é um campo exclusivo dos especialistas credenciados, tampouco se restringe ao espaço delimitado pelas instituições de formação artística. A arte é um patrimônio da humanidade, mas alguns cuidados precisam ser tomados para não reduzi-la à condição de ornamentação do fazer científico. Para Gombrich (2000, p. 15), 
Nada existe realmente a que se possa dar o nome de arte. Existem somente artistas. Outrora, eram homens que apanhavam um punhado de terra colorida e com ela modelavam toscamente as formas de um bisão na parede de uma caverna; hoje, alguns compram suas tintas e desenham cartazes para tapumes; eles faziam e fazem muitas outras coisas. Não prejudica ninguém dar o nome de arte a todas essas atividades, desde que se conserve em mente que tal palavra pode significar coisas muito diversas, em tempos e lugares diferentes, e que Arte com A maiúsculo não existe.

\section{Apontamento 2}

Os dados apresentados nas Tabelas 1 e 2 mostram que a concorrência entre os projetos inscritos nos editais do Pibex e do Procarte e o número de bolsas ofertadas é demasiado flutuante. No entanto, os dois últimos Editais (002/2016 e 001/2017) denotaram certa disparidade. Enquanto o Pibex atingiu uma relação de dois projetos por bolsa, o Procarte não teve nenhuma concorrência, pois o número de projetos inscritos foi estatisticamente inferior ao número de bolsas ofertadas. No Edital 001/2017 do Procarte, não houve concorrência alguma, pois nove projetos foram inscritos para um total de dez bolsas.

O cruzamento entre as planilhas publicadas com os resultados finais dos editais do Procarte e do Pibex revelou a existência de dados muito interessantes. Os projetos "Física de instrumentos musicais", "Cinema e educação: problematizando o cotidiano" e "Buena onda: o rádio na disseminação da arte e da cultura hispânica e no aprendizado da língua espanhola" foram apresentados ao Pibex ${ }^{3}$, mas, como não conseguiram ser classificados com recursos, foram reenviados aos editais subsequentes do Procarte, alcançando, desta vez, o almejado apoio institucional.

Essa ocorrência provoca algum estranhamento, afinal, não seria o Procarte um programa específico para projetos de arte e cultura? Qual é a razão dessa migração do Pibex para o Procarte? A elevada concorrência nos editais do Pibex deve ter provocado essas migrações, do contrário, por que os projetos não foram reestruturados e novamente encaminhados ao Pibex? Ou então, por que os projetos não foram encaminhados ao Procarte logo na primeira tentativa? Não é possível responder a todos esses questionamentos, mas houve um acontecimento inédito durante o processo de seleção de projetos encaminhados para o Edital 001/2016 dos dois programas que indica algumas possibilidades.

O projeto "Comunidades do Campo: conhecendo seus sujeitos, saberes e realidades" foi enviado simultaneamente para o Pibex e para o Procarte, tendo sido aprovado com recursos em ambos. Esse constrangedor acontecimento motivou o acréscimo imediato de uma nova cláusula a ser efetivada a partir do Edital 002/2016: “Não é permitido o envio de propostas idênticas para os editais Pibex e Procarte. Parágrafo único: O não cumprimento desse item acarretará a desclassificação dos dois projetos" (PROCARTE, 2016, p. 5).

A impossibilidade de acumular os recursos de dois programas distintos obrigou o coordenador do referido projeto a fazer uma escolha, que foi direcionada ao Pibex, uma decisão coerente com os objetivos de uma proposta que não estabelece uma relação direta com o fazer artístico-cultural. No ano seguinte, esse mesmo projeto foi encaminhado ao Pibex pela segunda vez (Edital 001/2017), tendo sido novamente classificado com recursos.

A escolha de todos esses proponentes pelo Pibex pode sinalizar a existência de uma hierarquização de valores entre os dois programas. De acordo com Silvio Diogo (2016, p. 38): “O Procarte não é uma batalha ainda ganha, que podemos considerar vencida. É algo que precisa se manter em certo estado de tensão para que nós possamos garantir a permanência de um apoio específico à arte e à cultura na universidade".

Sobre essa controversa discussão, interessante evocar o "Cine Mercúrio: movimentação de culturas e linguagens", um dos projetos mais antigos em atividade (registrado na Proexc/UFVJM desde 2009) e que conquistou diversos editais do Pibex. O surgimento do Procarte em 2012 não instigou os coordenadores do "Cine Mercúrio" a mudar de programa, pois o projeto continuou a ser sistematicamente encaminhado ao Pibex.

O "Cine Mercúrio", embora nunca tenha sido encaminhado ao Procarte, é um exemplo categórico de um projeto que atende integralmente às exigências e expectativas desse programa. Essa recusa, de alguma forma, fortalece a tese na qual o Pibex goza de maior prestígio junto à comunidade acadêmica 
em detrimento do Procarte.

\section{Apontamento 3}

Alguns projetos apresentados ao Procarte denunciam uma tentativa de adequação indevida de propostas que não estabelecem qualquer relação com as áreas da cultura e da arte, o que talvez tenha sido motivado pela elevada concorrência do Pibex.

"A interferência da música clássica sobre o comportamento e a produção de leite em vacas" é um dos 13 projetos encaminhados ao Edital 002/2014 do Procarte. A música, erudita ou popular, talvez influencie o comportamento desses mamíferos, mas esse tipo de abordagem não estabelece nenhum diálogo com a cultura. A música, nesse contexto, é trazida como fenômeno puramente acústico, desconsiderando sua intrínseca relação histórica e sociocultural. O projeto foi desclassificado, mas o caso, em alguma medida, reflete a falta de compreensão da comunidade acadêmica sobre as diferenças entre o Procarte e o Pibex, que poderia ter acolhido essa proposta através da área temática $\mathrm{n}^{\circ} .7$ (Tecnologia e Produção).

Uma situação semelhante se observa no projeto "Como é possível a pintura do ambiente interferir na produção do leite?", encaminhado para esse mesmo Edital (002/2014). Essa proposta, também desclassificada, evidencia uma compreensão completamente equivocada sobre o significado da Pintura enquanto linguagem e arte.

O Edital 002/2016 do Procarte trouxe o projeto "Inserindo os insetos na arte: oficinas motivacionais de incrustação de insetos em resina", um terceiro exemplo dessa "adequação indevida". A proposta não foi classificada, mas revela a imprecisão com a qual a comunidade acadêmica se apropria da noção de arte, que se expressa como técnica (techné), mas não se limita ao seu aspecto manualinstrumental, abarcando também "as artes superiores e belas artes" (HEIDEGGER, 2007, p. 380). A incrustação de insetos em resina é um processo relativamente lúdico, mas o elemento artístico-criativo não se encontra presente nesse tipo de procedimento que liquida por completo aquilo que Benjamin (1994, p. 169) define como "valor tradicional do patrimônio da cultura".

\section{Apontamento 4}

A grande incidência de projetos renovados, ou seja, projetos que se mantêm durante duas, três ou mais edições do Procarte (Tabela 3) é um dado preocupante. É evidente que um projeto, de pesquisa ou extensão, precisa de um tempo razoável para amadurecer e atingir a excelência acadêmica. Não obstante, muitos projetos são reapresentados com o conteúdo praticamente idêntico ao roteiro original, trazendo apenas mais alguns pequenos acréscimos de modo a atender às exigências do Art. 9.9 do Edital: "Os projetos em execução e reapresentados para o Edital Procarte deverão indicar os resultados obtidos até o momento e a justificativa para a sua continuidade" (PROCARTE, 2017, p. 7).

Um projeto, em geral, parte de uma perspectiva abstrata, de uma hipótese a ser comprovada. Mas, depois de ser colocado à prova por 12 meses, não seria preciso reavaliar procedimentos, objetivos e, por conseguinte, reescrever a proposta? Certamente, sem contar que é mais fácil para um projeto em andamento ser reapresentado do que para um projeto estreante, o que coloca os novos proponentes em franca desvantagem.

O elevado número de projetos renovados ( $90 \%$ no último edital) e a significativa diminuição de novas propostas trazem mais três indagações: será que a comunidade acadêmica da UFVJM está chegando ao limite de sua contribuição no campo da cultura e da arte? Será que essa retração deve-se à inexistência de cursos de Artes nos campi da UFVJM? Será que essa situação colocará o programa em xeque? Não se sabe, mas é preciso levar em consideração que a UFVJM congrega cerca de mil proponentes em potencial, observando-se uma população de aproximadamente 700 professores e 400 técnicos.

Esse quadro pode provocar diminuição na oferta anual de bolsas destinadas ao Procarte ou, então,

Tabela 3 - Editais do Procarte e porcentagem de projetos renovados.

\begin{tabular}{cccccccccc}
\hline $001 / 2012$ & $001 / 2013$ & $002 / 2013$ & $001 / 2014$ & $002 / 2014$ & $001 / 2015$ & $002 / 2015$ & $001 / 2016$ & $002 / 2016$ & $001 / 2017$ \\
\hline $0 \%$ & $0 \%$ & $0 \%$ & $60 \%$ & $20 \%$ & $20 \%$ & $37 \%$ & $90 \%$ & $70 \%$ & $90 \%$ \\
\hline
\end{tabular}

Fonte: Tabela elaborada com base nos dados disponibilizados pela Diretoria de Cultura (Proexc/UFVJM). 
causar redistribuição dos recursos, pois o número de projetos "classificados sem recursos" pelos editais do Pibex, como será discutido em seguida, costuma ser bastante elevado.

\section{Apontamento 5}

Muitos projetos encaminhados aos editais do Pibex e do Procarte entre 2013 e 2017 foram classificados, mas, devido à limitação orçamentária, não foram contemplados com recursos (Tabela 4).

Em relação ao Procarte, 11 projetos foram "classificados sem recursos". Já o Pibex atingiu um total de 262 projetos "classificados sem recursos". Quase a totalidade desses projetos foi engavetada, o que provoca mais uma indagação: por que projetos classificados e, portanto, portadores de propostas interessantes e perfeitamente exequíveis, não foram desenvolvidos? A falta dos recursos de custeio não parece ser um empecilho para a execução de um projeto, pois esse apoio limita-se basicamente a serviços gráficos, materiais de almoxarifado e combustível (sem diárias para motorista).

No item "orçamento" do roteiro para elaboração de projetos do Procarte e Pibex, consta uma tabela a ser preenchida com a "alternativa para execução do projeto se o item não estiver disponível" (PROCARTE, 2017, p. 2), ou seja, os proponentes precisam estar preparados para lidar com a possível falta de recursos de custeio. Um dos critérios de avaliação das propostas refere-se justamente à "viabilidade logística, técnica e operacional da proposta compatível com a infraestrutura existente na UFVJM" (PROCARTE, 2017, p. 7), que contabiliza um total de dez pontos. Se a indisponibilidade de recursos de custeio não é motivo para o engavetamento dos projetos "classificados sem recursos", a impossibilidade de ter um discente-bolsista na equipe de trabalho parece ser a principal razão.

O bolsista é a figura-chave na execução de um projeto. Ele atua como mediador entre o coordenador e a comunidade. Como diria a Diretora de Cultura, Léa Sá Fortes (2017, acervo pessoal)): "São os estudantes que estarão no tête-à-tête com a comunidade, até porque é esse o retorno da extensão para o estudante, essa aproximação, esse estreitamento com a sociedade". Sem o bolsista, o desenvolvimento de um projeto de extensão torna-se inviável. Ademais, a participação de estudantes nas ações de extensão é compulsória, pois o formulário de registro de projetos prevê em campo específico o preenchimento de dados sobre a participação de estudantes na equipe executora.

O primeiro objetivo do Procarte, que parece ser o mais importante, é: “Contribuir com a formação dos discentes a partir da interação com as manifestações culturais e artísticas das regiões de abrangência da UFVJM" (PROCARTE, 2017, p. 2). O Pibex segue a mesma orientação, indicando como objetivos 1, 5 e 6 do programa: "Estimular a participação da comunidade universitária em ações de extensão, especialmente a participação de discentes; Contribuir com a formação dos discentes a partir da interação com a realidade da população brasileira; Qualificar os discentes para os desafios enfrentados no mundo atual em relação à atuação profissional e ao exercício da cidadania" (PIBEX, 2017, p. 1).

Cabe aos coordenadores dos projetos "selecionar e indicar para bolsista, discente com perfil adequado e formação compatível para as atividades previstas no projeto" (PROCARTE, 2017, p. 4), mas como encontrar na UFVJM um discente com esse "perfil adequado" para desenvolver ações de dança, teatro, música, cinema ou artes visuais? O pouco tempo disponível para o processo de seleção dos candidatos também dificulta o cumprimento dessa exigência, pois se dispõe em média de dez dias úteis entre a divulgação do resultado final do edital e o prazo de entrega da documentação do bolsista selecionado.

O "Coral Cênico UFVJM", contemplado por três vezes pelo Procarte (Editais 001/2015, 001/ 2016 e 001/2017), parece ser um bom exemplo dessa problemática. Esse projeto, cadastrado na área da Música, tem como objetivo geral proporcionar aos participantes um espaço de estudo e prática do canto coral com ênfase na encenação teatral. Para que possa alcançar esse objetivo com algum êxito, o projeto precisa dispor de profissionais devidamente habilitados em educação musical, mas como selecionar entre os estudantes da UFVJM um bolsista com "perfil adequado" e "formação compatível" com as exigências técnicas e acadêmicas de um coral cênico? Essa sinergia entre coordenador e bolsista

Tabela 4 - Projetos classificados sem recursos entre 2013 e 2017 nos editais Pibex e Procarte.

\begin{tabular}{lccccccccc}
\hline EDITAL & $001 / 2013$ & $002 / 2013$ & $001 / 2014$ & $002 / 2014$ & $001 / 2015$ & $002 / 2015$ & $001 / 2016$ & $002 / 2016$ & $001 / 2017$ \\
\hline Pibex & 10 & 10 & 29 & 16 & 23 & 58 & 5 & 64 \\
Procarte & - & 2 & 1 & 3 & - & - & 47 & - & 1 \\
\hline
\end{tabular}


é possível, mas as chances são reduzidas.

A presença do discente-bolsista é realmente fundamental para a plena execução de um projeto. Resta saber se os estudantes também têm consciência dessa responsabilidade em atuar como embaixadores da instituição frente à comunidade, pois o número de reclamações formais e informais de coordenadores de projetos em relação ao não cumprimento dos "compromissos do discente-bolsista" previstos no edital do Procarte (2017, p. 5-6) é bastante elevado.

A desvalorização da extensão, discutida com eloquência por Moita e Andrade (2009) e apontada com preocupação por todos os entrevistados, talvez influencie essas condutas muitas vezes irresponsáveis da parte dos estudantes, o que não acontece com tanta regularidade nas ações de ensino e pesquisa, cujos mecanismos de frequência e avaliação parecem ser mais efetivos.

\section{Conclusões}

O papel da extensão universitária na formação dos acadêmicos é evidente, embora parte considerável dos discentes consiga integralizar o curso de graduação sem nunca ter participado de uma ação extensionista, um distanciamento que deve ser minimizado com a creditação da extensão universitária. Essa ausência, em parte, reflete uma compreensão de universidade difundida pelos próprios docentes, que acabam privilegiando o ensino e a pesquisa em detrimento da extensão, contrariando, desse modo, o artigo 207 da Constituição Federal Brasileira. Esse assunto é controverso. Para André Covre: "Existe uma tendência a considerar menor uma atividade de extensão, que não é só uma tendência institucional, mas de política nacional e de carreira".

Em relação às ações específicas vinculadas à arte e à cultura, Roberto Amaral (2016, p. 34) afirmou que elas são "o aspecto fundamental no processo formativo dos estudantes". Todos os outros entrevistados também reconheceram essa potência presente nas manifestações artístico-culturais. Para todos eles, esse tipo de vivência articula práticas e saberes que estão distantes do cotidiano dos acadêmicos, o que é verdadeiramente enriquecedor. A oportunidade de interagir com estudantes de outras áreas do conhecimento também é um aprendizado singular e igualmente significativo. Os teatros universitários, em sua origem, surgiram dessa necessidade legítima dos estudantes em buscar um espaço de interlocução entre arte, política, ciência e filosofia na rígida estrutura da instituição.

O investimento na produção e gestão de espaços de arte e cultura pode ser um caminho para a superação de um estado psicossocial de apatia e alienação que Almeida (1994) denominou por "infância cultural", uma espécie de rejeição às "coisas da cultura que demandem esforço de entendimento, sensibilidade ou atenção, como filmes, músicas e textos considerados difíceis ou complexos" (ibidem, p. 27-28).

Para Roberto Amaral (2016, p. 35), o Procarte é “um ganho político". Apesar de suas limitações, o programa tem movimentado a vida cultural da universidade, proporcionando novas experiências de formação não apenas aos estudantes, como também aos técnicos, docentes e membros da comunidade externa envolvidos com os projetos. De acordo com Silvio Diogo (2017, p. 38):

É importante recuperar a dimensão do sonho, a dimensão da projeção do futuro, como uma dimensão fundamental da universidade, porque sem ela nós não nos movemos pelos desejos, pela arte, pela poesia, pela dança, pela música. Esses são os imãs, que nos chamam, convocam para movimentar, para criar, para produzir e para também construir uma universidade.

Como aparente resposta frente à baixa oferta de ações de extensão ligadas à arte e à cultura, o Reitor da UFVJM, no uso de suas atribuições, publicou o Edital n ${ }^{\circ} 125$, de 20 de outubro de 2017, que trata do processo simplificado para a contratação provisória de dois professores visitantes das áreas da Música e Artes Cênicas.

A presença de dois especialistas deve fortalecer a área da cultura e especialmente a área da arte, mas é notório que esse tipo de empreendimento, essencialmente vinculado às políticas culturais, necessita de um tempo muito maior do que a vigência do contrato a ser estabelecido ( 1 a 2 anos).

Se a breve passagem desses mensageiros de Apolo e Dionísio não for suficiente para revolucionar o panorama cultural da instituição e reacender as discussões sobre a implementação de cursos de Artes nos campi da UFVJM, teremos ao menos mais algumas oportunidades para fruir as sutilezas e 
encantos da arte e verificar se ela realmente contribui com a formação cultural e acadêmica dos estudantes.

\section{Agradecimentos}

Agradecimento especial a toda equipe da Proexc/UFVJM pelo suporte e disponibilidade em debater as questões levantadas neste artigo, em especial ao poeta Silvio Diogo (in memoriam).

\section{Referências}

AGUIAR, N. C.; DINIZ, T. C.; CAMBRAIA, R. P.; CARVALHO, M. A. Registro fotográfico da 'formiga de ouro' na Serra do Espinhaço Meridional, Brasil. Expressa Extensão, Pelotas, v. 21, n. 1, p. 187195, 2016. Disponível em <http:// periodicos.ufpel.edu.br/ojs2/index.php/expressaextensao/ article/view/7538> Acesso em 3 dez. 2017.

ALMEIDA, M. J. Imagens e Sons: a nova cultura oral. São Paulo: Cortez, 1994.

AMARAL, R. Entrevista. In: SANTOS, R. B.; CARVALHO, R. V. L. Programa de Bolsas de Apoio à Cultura e à Arte: considerações sobre extensão universitária e formação acadêmica. Diamantina: Departamento de Educação Física da UFVJM, 2016, p. 32-35.

ANDRADE, M. Oração de Paraninfo (1935). Pro-Posições, Campinas, v. 16, n. 1 (46), jan./abr. 2005, p. 261-270.

BENJAMIN, W. A obra de arte na era da reprodutibilidade técnica. In: BENJAMIN, W. Magia e técnica, arte e política. Tradução de Sérgio Paulo Rouanet. 7. Ed. São Paulo: Editora Brasiliense, 1994. (obras escolhidas), p. 165-196.

BERMAN, A. A prova do estrangeiro: cultura e tradução na Alemanha romântica. Tradução de Maria Emília Pereira Chanut. Bauru: EDUSC, 2002.

BOUTÉ, G. O espelho e a noite. In: CLAUDEL, C. Esculturas, desenhos e pinturas. Tradução de Maria Lucia Montes, Luciano Lapretto e Lígia Cardon. São Paulo: Pinacoteca do Estado, 1997, p. 193194.

BRASIL. Ministério da Cultura. As Metas do Plano Nacional de Cultura. Brasília: MinC, 2012, 111 p.

DIOGO, S. Entrevista. In: SANTOS, R. B.; CARVALHO, R. V. L. Programa de Bolsas de Apoio à Cultura e à Arte: considerações sobre extensão universitária e formação acadêmica. Diamantina: Departamento de Educação Física da UFVJM, 2016, p. 36-38.

FORPROEX. Política Nacional de Extensão Universitária. Manaus: Fórum de Pró-Reitores de Extensão das Universidades Públicas Brasileiras, 2012, 68 p.

GOMBRICH, E. A História da Arte. Tradução de Álvaro Cabral. 16. Ed. Rio de Janeiro: LTC, 2000.

HEIDEGGER, M. A questão da técnica. Tradução de Marco Aurélio Werle. Scientiæ Studia, São Paulo, v. 5, n. 3, 2007, p. 375-398.

MOITA, F. M. G. S. C.; ANDRADE, F. C. B. de. Ensino-pesquisa-extensão: um exercício de indissociabilidade na pós-graduação. Revista Brasileira de Educação, Rio de Janeiro, v. 14, n. 41, maio/ago. 2009, p. 269-393. Disponível em: <http://www.scielo.br/pdf/rbedu/v14n41/ v14n41a06.pdf>. Acesso em 24 set. 2017.

PIBEX. Programa Institucional de Bolsas de Extensão. (edital 001/2017). Pró-Reitoria de Extensão e Cultura da Universidade Federal dos Vales do Jequitinhonha e Mucuri, 2017, 10 p. Disponível em: <http://www.ufvjm.edu.br/proexc/procarte/2697-2017.html>. Acesso em 13 jul. 2017.

PROCARTE. Programa de Bolsas de Apoio à Cultura e à Arte. (edital 001/2017). Pró-Reitoria de Extensão e Cultura da Universidade Federal dos Vales do Jequitinhonha e Mucuri, 2017, 10 p. Disponível em: <http://www.ufvjm.edu.br/proexc/procarte/2697-2017.html>. Acesso em 13 jul. 2017. 
PROEXC/UFVJM. Regulamento das ações de extensão universitária. Pró-Reitoria de Extensão e Cultura da Universidade Federal dos Vales do Jequitinhonha e Mucuri, 2008, 18 p. Disponível em: <http:/ /www.ufvjm.edu.br/proexc/regulamentoacoes.html>. Acesso em 15 jul. 2017.

SANTOS, R. B.; CARVALHO, R. V. L. Programa de Bolsas de Apoio à Cultura e à Arte: considerações sobre extensão universitária e formação acadêmica. Diamantina: Departamento de Educação Física da UFVJM, 2016, 38 p. (trabalho de conclusão de curso).

SARAIVA, F. R. S. Dicionário Latino-Português: etimológico, prosódico, histórico, geográfico, mitológico, biográfico. 12. Ed. Belo Horizonte: Livraria Garnier, 2006.

SAVIANI, D.; MARTINS, M. F.; CARDOSO, M. M. R. Catarse na pedagogia histórico-crítica: a concepção de Saviani (entrevista). Crítica Educativa, Sorocaba/SP, vol. 1 (n. 1), jan./jun. 2015, p. 163217.

SCHLEIERMACHER, F. Hermenêutica: Arte e Técnica da Interpretação. Tradução e apresentação de Celso Reni Braida. 8. Ed. Petrópolis: Vozes, 2008.

UNAMUNO, M. Del sentimiento trágico de la vida en los hombres y en los pueblos. Espanha: Alianza Editorial, 1986.

Recebido para publicação em 05/02/2019 e aprovado em 09/09/2019. 